\title{
DE PANTEÓN REAL A RELICARIO: EL DEBATE FINAL EN TORNO AL PROYECTO DE FRANCISCO DE HERRERA EL MOZO PARA LA CAPILLA REAL DE SEVILLA
}

\author{
FROM ROYAL MAUSOLEUM TO SHRINE: \\ THE FINAL DISCUSSION TO THE PROJECT OF \\ FRANCISCO DE HERRERA THE YOUNGER DESTINED \\ TO THE ROYAL CHAPEL OF SEVILLE
}

\author{
Antonio García Baeza \\ antonioleria@gmail.com
}

\begin{abstract}
Uno de los proyectos decorativos que más discusiones planteó en el barroco sevillano fue la adecuación de la Capilla Real de Sevilla a panteón real y relicario de San Fernando. Su ejecución se prolongó medio siglo y en ella tuvieron parte activa la corte y las autoridades eclesiásticas y civiles de la ciudad. Un debate que se movió en torno a las diferentes trazas que realizó Francisco de Herrera el Mozo para el retablo-tabernáculo de la Virgen de los Reyes y la urna-relicario del nuevo bienaventurado, y que pusieron de relieve las diferentes tendencias estéticas en las que se mueve el panorama local.

Palabras clave: diseño; orfebrería; retablo; Carlos II; Barroco.
\end{abstract}

The adaptation of the Royal Chapel of Seville to a royal mausoleum and shrine of Saint Ferdinand was one of the most discussed decorative projects during the Baroque period. Its execution was prolongued half a century, and the Court and the eclesiastical and civil authorities of the city also took part in it. A discussion that revolved around the different traces made by Francisco de Herrera the Younger in order to design the altarpiece-tabernacle of Our Lady of the Kings and the urn-shrine of Saint Ferdinand, which highlighted the different aesthetic trends in which the local panorama moves.

Keywords: design; jewelery; altarpiece; Carlos II; Baroque.

A las 11 de la mañana del martes 26 de mayo de 1677 , los porteros de la catedral de Sevilla procedieron a cerrar el inmueble para dar comienzo al acto de 
separación de los cuerpos regios conservados en la Capilla Real ${ }^{1}$. Acto seguido, los féretros de Alfonso X el Sabio y Beatriz de Suabia fueron independizados de los de Fernando III y colocados en una peana dispuesta sobre la mesa de altar. El arzobispo y el presidente de la capilla mostraron las llaves que obraban en su poder, abrieron los ataúdes y los reconocieron. Posteriormente, los capellanes trasladaron sendos cuerpos a hombros hasta la sala capitular de la institución y los depositaron sobre un bufete con sobremesa de terciopelo, cubriéndolos con un paño de rico brocado y una almohada en la que descansaba la corona imperial. Finalmente, los asistentes cerraron la puerta de la estancia y dispusieron las cajas vacías en los arcosolios que se abren junto a la reja de la capilla. Veinticuatro horas más tarde comparecieron en el mismo lugar, y a puerta cerrada, las autoridades de la ciudad: arzobispo, deán, canónigos, capitulares, asistente y diputados munícipes. Volvieron a abrir la sala y los presentes dieron fe sobre la veracidad de los restos que fueron trasladados en procesión hasta los arcosolios -adornados previamente con doseles y sitiales atendiendo a la naturaleza de los sepultados ${ }^{2}-$, donde quedaron definitivamente depositados dentro sus sepulcros bajo dos llaves custodiadas, nuevamente, por el presidente de la capilla y el prelado. De todo este proceso, así como de la redacción de los hechos, se encargó el canónigo Juan de Tejada, en la que fue su última gran aportación a la causa fernandina ${ }^{3}$.

El fervor de Mariana de Austria por el santo monarca no se resintió en ningún momento durante el largo proceso de canonización y la posterior puesta en valor de sus reliquias. Al contrario, en todo momento anduvo atenta a las necesidades de la causa ${ }^{4}$. En 1675 había conseguido la aprobación del ritual propio para el segundo nocturno de su oficio ${ }^{5} \mathrm{y}$, el 4 de agosto de 1677, pidió que le

1 Todo el acto de separación de los cuerpos está reseñado en 1677, mayo, 27. Sevilla. Capítulo. Archivo de la Catedral de Sevilla (A.C.S.), Capilla Real, Autos Capitulares, lib. 6, ff. 139-140.

2 1674, julio, 16. Sevilla. Capítulo. A.C.S., Capilla Real, Autos Capitulares, lib. 6, f. 65v; 1677, mayo, 22 y 1677, mayo, 24. Sevilla. Capítulos. A.C.S., Capilla Real, Autos Capitulares, lib. 6, ff. 137-18v. Es interesante el papel destacado del canónigo Juan de Tejada en todo este proceso, pues a él se le pide consejo de cómo disponer los cuerpos y llevar a cabo la ceremonia.

3 1677, junio, 19. Capítulo. A.C.S., Capilla Real, Autos Capitulares, lib. 6, f. 140v.

4 1677, agosto, 4, 10, 13 y 17, octubre, 19. Sevilla. Capítulos. A.C.S., Capilla Real, Autos Capitulares, lib. 6, ff. 142-145v y $147 \mathrm{v}-148$.

${ }^{5}$ MORALES, Alfredo J.: "Rey y santo. Ceremonial por Fernando III en la Catedral de Sevilla”, en MÍNGUEZ, Víctor (ed.): Visiones de la monarquía hispánica. Valencia, 2007, p. 113. En 1675 se aprueba el ritual propio del santo para el segundo nocturno de su oficio. 
fuese enviado el anillo que el santo rey custodiaba sobre el pecho, remitiéndosele la sortija en una caja de cristal con filigranas de oro a través del capitular Juan Galindo ${ }^{6}$.

No obstante, la nueva política económica impuesta por don Juan de Austria impedía acometer a corto plazo cualquier planeamiento de envergadura sobre la Capilla Real. De tal modo que, aunque Carlos II ordenó al asistente de Sevilla que dispusiese los medios necesarios para reubicar el cuerpo del santo en el altar de la Virgen de los Reyes "en la forma que montaba vn diseño que, así mismo, venía con la dicha carta elegido" por el Consejo de Castilla ${ }^{7}$, y a pesar de la buena disposición del munícipe ${ }^{8}$, la paupérrima realidad impidió que se llegaran a concretar sus deseos en hechos. La propia Iglesia de Sevilla había caído en la desesperanza con este tema y llegó a pedir a Francisco Leonardo Guerra, emisario de la causa en la corte, que, dada la poca esperanza que tenían en que pudiese alcanzar la renta que solicitaban a Palacio para la capilla, fuese recogiendo los papeles y la estancia que ocupaba en Madrid para volver en cuanto se le diese aviso ${ }^{9}$. $Y$ es que la falta de financiación -a pesar del esfuerzo regio y capitular por hacer acopio de bienes en ultramar ${ }^{10}$ - y las distintas contradicciones técnicas surgidas, habían llevado al traste cualquier mínima intención de dar inicio a la obra. Llegando a tal punto la ruina del inmueble que debieron tabicar las ventanas de la linterna para impedir que la lluvia dañara los santos restos ${ }^{11}$, pues se encontraba a la intemperie y solo cubiertos con "un mal paño muy uiejo y roto [...] todo hecho pedasos" 12 .

Hubo que esperar hasta 1681 para vislumbrar un nuevo interés generalizado por el decoro de la capilla gracias a la entrada oficial de dos nuevos actores: Andrés de la Concha Zapata, regente de la Real Audiencia, y Ambrosio de Spínola,

${ }^{6}$ SANCHO CORBACHO, Heliodoro: "Historia de la construcción de la urna de plata que contiene los restos de San Fernando", Estudios de Arte Sevillano, 1973, pp. 104 y 116.

7 1677, octubre, 19. Sevilla. Capítulo..., doc. cit., f. $147 \mathrm{v}$.

8 1677, octubre, 21. Sevilla. Capítulo. A.C.S., Capilla Real, Autos Capitulares, lib. 6, ff. $148-148 \mathrm{v}$.

9 1678, octubre, 29. Sevilla. Capítulo. A.C.S., Capilla Real, Autos Capitulares, lib. 6, f. $171 \mathrm{v}$.

${ }^{10} \mathrm{Al}$ respecto se conserva una colección documental sobre tres licencias de navíos procedentes de México que se pretenden aplicar a la causa de la urna y que se reclaman en 1677 en el Archivo General del Arzobispado de Sevilla (A.G.A.S.), Varios VIII, San Fernando, leg. 10.739 , exp. 8.

11 1679, septiembre, 10. Sevilla. Capítulo. A.C.S., Capilla Real, Autos Capitulares, lib. 6, ff. 190v-191.

12 1681, septiembre, 24. Sevilla. Capítulo. A.C.S., Capilla Real, Autos Capitulares, lib. 6, ff. 228-228v. Esta noticia ha sido recogida previamente en SANCHO CORBACHO, H.: "Historia...", op. cit., pp. 104 y 116. 
arzobispo de Sevilla. Sobre el munícipe recayó la responsabilidad de solventar las eternas trabas económicas aportando soluciones prácticas mediante iniciativas activas, como la imposición de nuevas medidas recaudatorias basadas en la retención de medio real sobre el arbitrio del vino ${ }^{13}$, mientras que el prelado se encargó de precisar el diseño final del proyecto, sin mediar más entendimiento que el suyo propio ${ }^{14}$.

En agosto todo parecía dispuesto para dar comienzo a la obra. Carlos II trasmitió al regente una cédula sobre la disposición de la urna fernandina. Nada más conocer la noticia los capellanes volvieron a apoderar a Francisco Leonardo y a Pedro Muñiz como diputados para realizar el seguimiento de su construcción según los planteamientos aprobados por su majestad ${ }^{15}$. El 24 de septiembre el político instó a los capellanes a bajar la imagen de la Virgen de los Reyes de su tabernáculo y entronizarla, en el menor tiempo posible y de manera provisional, sobre el altar de San Fernando ${ }^{16}$. Un traslado temporal que venía obligado por las obras de adaptación del hueco del testero que, según los planes previstos, debía acoger al nuevo retablo en el que se dispondrían las reliquias del conquistador a los pies de la imagen mariana, tal y como lo había dispuesto el monarca en su testamento ${ }^{17}$ y se venía contemplando desde hacía una década.

Pronto se torcieron estos esfuerzos. El 1 de octubre los capellanes advirtieron sobre las desavenencias surgidas entre el arzobispo, el deán, el cabildo de la catedral y el gobierno de la ciudad a cuenta de la obra, viéndose obligados a paralizarla por no haber informado a su majestad de su inicio. A su favor adujeron que habían seguido órdenes reales y del consistorio. Pero, a fin de aquietar los ánimos, cesaron en su empeño hasta recabar un nuevo consenso. Mientras tanto se pidió a todos los capellanes que procurasen no tratar el tema ni en público ni en

${ }^{13}$ Noticia con fecha de 17 de junio de 1681 recogida en SANCHO CORBACHO, H.: "Historia...", op. cit., pp. 104 y 116. De la que no hemos podido dar fe archivística.

14 1680, noviembre, 16. Sevilla. Capítulo. A.C.S., Capilla Real, Autos Capitulares, lib. 6, f. 206v: el Consejo de Castilla remite a los capitulares nuevamente un diseño de la urna y del adorno que la acompaña; 1681, marzo, 15. Sevilla. Capítulo. A.C.S., Capilla Real, Autos Capitulares, lib. 6, f. 214: se obliga al Arzobispo a hacer un informe que ha de enviar a Carlos II.

15 1681, agosto, 4. Sevilla. Capitulo. A.C.S., Capilla Real, Autos Capitulares, lib. 6, f. 224. Esta noticia ha sido recogida previamente en SANCHO CORBACHO, H.: "Historia...", op. cit., pp. 104 y 116, pero la consulta directa ha supuesto una nueva interpretación que difiere del regesto realizado por el profesor, ya que, con seguridad, a fines de noviembre la Virgen de los Reyes se encuentra sobre el altar de San Fernando. Así se contempla en 1681, noviembre, 21. Sevilla. Capitulo. A.C.S., Capilla Real, Autos Capitulares, lib. 6, f. 231v.

16 1681, septiembre, 24. Sevilla. Capítulo ..., doc. cit., ff. 228-228v.

17 1682, septiembre, 5. Sevilla. Capitulo. A.C.S., Capilla Real, Autos Capitulares, lib. 6 , f. $305 \mathrm{v}$. 
la intimidad, y que no se hablase mal de ningún prelado catedralicio, bajo pena de una posible multa de 500 reales aplicados a la fábrica ${ }^{18}$.

A principios de diciembre, el regente local carteó al monarca con dos pretensiones. La primera concerniente a la vigencia y reafirmación de la real cédula expendida el 7 de noviembre de 1634 por Felipe IV a propósito de ciertos privilegios concedidos a la Iglesia de Sevilla como ayuda a los gastos de la canonización del santo rey, adorno de la capilla y reubicación de su reliquia ${ }^{19}$. Y la segunda, dándose por enterado sobre las piezas que se debían de ejecutar en el frente de la capilla, remitiéndole el dibujo de la urna y el altar. Carlos II contestó que, antes de tomar cualquier determinación al respecto de los privilegios otorgados por su progenitor, se le deberían remitir las cuentas del cobro y gastos de los arbitrios que se habían recibido hasta la fecha, así como el de todas las limosnas que habían llegado de la carrera de Indias y que fueron destinados en la capilla ${ }^{20}$.

Significativamente, a partir de este instante Carlos II y el Consejo de la Cámara resolvieron tramitar todos los movimientos concernientes a las obras de la Capilla Real con el arzobispo como único interlocutor, dejando de lado a sus propios capellanes hispalenses, a los que obligó a disolver la diputación creada ad hoc compuesta por Francisco Leonardo y Pedro Muñiz, que pululaban en este asunto como versos sueltos proponiendo constantes alternativas artísticas sobre un proyecto consensuado y resuelto hace años ${ }^{21}$. De fondo se intuyen los desencuentros que desde hace algún tiempo venían socavando el seno de la Iglesia hispalense a

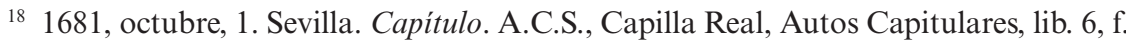
229. Tan tensa se encuentra la situación que se amonesta a Alonso de Bustos por los "muchos desórdenes con que prosegía [...] hablando mal de los capellanes de su magestad en público todas las noches, hasiendo portalejo con algunas personas a la puerta donde uiuieron los venerables saçerdotes, junto a la plaçuela del Atambor, hablando muchas palabras deshonestas a uoçes, escandalisando a toda la besindad sin auer puesto enmienda en esto".

19 1681, diciembre, 2. Madrid. Remisión del despacho de Carlos II al Arzobispo de Sevilla a propósito de la obra de urna y retablo y de la vigencia de la cédula real de siete de noviembre de 1634. A.C.S., Varios VIII, San Fernando, leg. 10.739, exp. 1. Por dicha cédula Felipe IV concede a la Iglesia de Sevilla que para ayudar a la causa mencionada se puedan conceder seis hidalguías, dar licencia para que se saquen 150.000 fanegas y realizar "dos visitas de nabíos en la carrera de las Yndias". 1634, noviembre, 7. Madrid. Copia de la Cédula Real concedida por Felipe IV para ayuda de la canonización de San Fernando.

20 1681, diciembre, 2. Madrid. Remisión..., doc. cit., f. [1].

${ }^{21}$ 1681, noviembre, 21. Sevilla. Capítulo... doc. cit., f. 231v. En esta idea hace hincapié un acta del cabildo de los capellanes reales en la que se nombra un mayordomo que debe recabar el dinero que se está recaudando como ayuda de costas a la obra propuesta en la que se da la orden por parte de la Cámara de Castilla para que el arzobispo sea el único que intervenga en la obra prevista, por lo que se obliga a disolver la Diputación del Santo Rey. 
propósito de ciertos pleitos de envergadura entre capitulares y capellanes ${ }^{22}$. Las palabras del monarca dirigidas al prelado fueron firmes: "tengo por bien remitiros el dicho dibujo para que lo reconoscáis, pues vnicamente os tengo cometida y encargada esta obra [a usted], esperando de buen celo y probidencia la dispondréis con el maior decoro y desencia al mayor culto de Nuestra Señora, y conforme a la voluntad y devosión que tubo y declaró el santo y señor rey". Así quedaba latente que, para la corte, el recuerdo de San Fernando estaba indisolublemente unido a la Virgen de los Reyes, y así debía explicitarse físicamente ${ }^{23}$.

A comienzos de 1682 el prelado, con intención conciliadora, venía apremiando al pintor Valdés Leal la conclusión de un nuevo diseño que le había parecido conveniente realizar, el cual, una vez acabado, remitiría al Consejo de Castilla para que fuese aprobado y se pudiese pasar a su inmediata ejecución, ya que era deseo del monarca que todo se obrase con rapidez ${ }^{24}$. Y así fue. El 5 de septiembre Spínola mandó a su majestad unas nuevas trazas para la urna del santo rey, "que le pareció disponer en mejor forma que la precedente aprobada", a fin de que fuesen aceptadas ${ }^{25}$. Al respecto se conserva en el Museo del Louvre un dibujo atribuido por Pérez Sánchez a las manos de Valdés que debe ponerse en relación con el diseño alternativo de la tapa del sarcófago (Figura 1) ${ }^{26}$. En ella se contempla a Fernando III sedente sobre un trono angélico, portando la corona, el orbe y la espada. A sus pies se disponen dos turbantes coronados y, a ambos lados, sendos putis que sostienen ramas de laurel y trofeos de batalla. Bajo el asiento se desarrolla una nube de motivos cartilaginosos y vegetales en cuyo frente se abre una puerta con las iniciales "S. I.", en clara alusión a la reliquia de San Isidoro que debía conservarse en su interior. A ambos lados del sitial se disponen el docto obispo hispalense y su hermano Leandro, en clara alusión al escudo del cabildo

${ }^{22}$ 1681, diciembre, 6. Sevilla. Capítulo. A.C.S., Capilla Real, Autos Capitulares, lib. 6, ff. $233 \mathrm{v}-234$. Sobre esta misma idea de desencuentro vuelve a incidir el auto capitular en el que los capellanes se dan por enterados de su expulsión temporal de las decisiones de la obra del testero, en tanto que se informa que, a partir de ese momento, cuando el arzobispo cruce la cancela de la capilla, se le reciba con el cortejo debido a su ilustrísima. SANCHO CORBACHO, H.: "Historia...", op. cit., pp. 133-134, recoge y transcribe un documento que resume el proceso de ejecución de las cajas de San Fernando desde 1681 hasta 1708 .

23 1681, diciembre, 2. Madrid. Remisión..., doc. cit., f. [1].

${ }^{24}$ SANCHO CORBACHO, H.: "Historia...", op. cit., pp. 104 y 117, dispone esta información al respecto de un cabildo fechado el 10 de enero de 1682, que no hemos podido cotejar pues su original no existe en la actualidad.

${ }^{25}$ 1682, septiembre, 5. Sevilla. Capítulo..., doc. cit., ff. 305v-318.

${ }^{26}$ San Fernando entronizado, Museo del Louvre, sig. 43253. Dibujo dado a conocer en PÉREZ SÁNCHEZ, Alfonso Emilio: Tres siglos de dibujo sevillano. Sevilla, 1995, pp. 242-243, $\mathrm{n}^{\circ}$ cat. 104 
de Sevilla. Lo cierto es que de esta alternativa nunca más se supo ${ }^{27}$, quizás porque el proyecto no fue del agrado de la curia sevillana o porque la corte quiso mantener los planes previstos. Lo cierto es que, en todo momento, solo se contemplaron como legítimos los planteamientos de Francisco de Herrera.

En septiembre aún andaba la capilla "sin el progreso que la piedad de sus devotos sevillanos solicitaban" debido a las irreconciliables diferencias que mantenían el arzobispo, el asistente y el regente local, habiendo pasado ya once meses desde que la Virgen se bajara de su altar. Para destramar la madeja, el munícipe solicitó a los capitulares altura de miras, pues habían transcurrido doce años desde la beatificación del monarca y se hacía muy necesaria la realización de una urna para la que el rey había dispuesto numerosos medios, acusándolos de la dilación de la obra por dejación de sus funciones. No en vano se había hecho acopio de 9.000 pesos, de a 26 reales de vellón cada uno, llegados de ultramar con destino al adorno de la capilla y entregados a la causa por la Casa de la Contratación que no se habían gastado.

A fin de paliar la cualquier tipo de duda, su majestad y la Cámara de Castilla respondieron a la última propuesta de Spínola con la remisión de las instrucciones definitivas de Herrera el Mozo - ahora maestro mayor de Obras Reales- sobre el sepulcro-relicario, en las que se reparaba extensamente en la explicación de los por qué técnicos, estéticos e iconográficos que había atendido ${ }^{28}$. La urna se compondría finalmente de seis piezas: pedestal, caja, arca interior, arca exterior, penacho y arco. El cofre que tiene contacto directo con el cuerpo lo proyectó en plata blanca, muy calado y con cuantiosos motivos labrados en ambas caras, atendiendo así a principios de decoro, exposición y profilaxis: "lo vno porque se a de gozar por entre los calados de los sobrepuestos, que siendo de plata blanca hará grande hermosura. Lo otro porque todo lo que a de estar más arrimado al cuerpo del santo deue ser de materia más noble. Lo otro, que en caso que se quieran quitar los sobrepuestos para limpiarlos quedará el cuerpo del santo solo con la capa lisa y el pabellón con bastante decençia, estando cerrada dentro de la otra sin necesidad de mudarle de su sitio"29. El arca que le continuaba debía ser de bronce dorado porque, según argumenta, un recipiente que resguarda a otro nunca debía ser tan noble como el primero, habiendo buscado un metal menos rico aunque su

${ }^{27}$ Pensamos, al igual que Fernando Quiles, que el papel de Valdés Leal en este proceso apenas tendría fuelle y supondría más un estado de la cuestión que un proyecto completamente cerrado. QUILES GARCÍA, Fernando: "En los cimientos de la Iglesia sevillana: Fernando III, rey y santo", Boletín del Museo e Instituto Camón Aznar, LXXV-LXXVI, 1999, p. 223, nota 108.

${ }_{28}$ 1682, diciembre, 15. Madrid. Parecer de don Francisco de Herrera sobre la obra del santo rey aprobado por su majestad y la Cámara. A.C.S., Gobierno, Asuntos Despachados, leg. 9.783 .

29 1682, diciembre, 15. Madrid. Parecer..., doc. cit., f. [1v]. 
ejecución fuera más costosa. Dicho material contaba, además, con la ventaja de que no necesitaba tanto mantenimiento y servía de contraste-visual y táctil-con la plata interior. Esta segunda caja debía estar cerrada en sus frentes por cristales, dejando contemplar el interior a la vez que lo preservaba. El arca más externa también debía realizarse en bronce dorado, si bien contaría con jaspes, o chapas esmaltadas, o cristales pintados, embutidos en el metal. Para mayor estabilidad y robustez del féretro proponía realizar ensambles metálicos en vez de almas de madera, dada su fragilidad, el cuantioso volumen que ocupa y su mala conservación.

Las cajas, insertas unas dentro de otras, debían colocarse sobre el pedestal original del sepulcro recrecido con un tambanillo de piedra que contuviera la inscripción de la aprobación canónica del culto. Esta ampliación supondría el aumento de media caña de altura -unos $75 \mathrm{~cm}-$ y debía ejecutarse con jaspes polícromos recorrido por distintas figuras de las virtudes en bronce fundido. Como elemento de transición entre la plataforma y el relicario propuso disponer distintos angelotes metálicos que sirvieran de asiento al joyero, dejando un espacio de aire entre ambas piezas. Herrera tuvo muy en cuenta en este nuevo proyecto las recomendaciones que en 1674 había realizado Bernardo Simón de Pineda ${ }^{30}$. Algunas fueron bien acogidas, como la idea de disponer un pabellón de tela en la parte superior que resguardara al difunto y la plata. Otras las desechó, como la colocación de las garras de fieras a los pies de la urna. "El poner ángeles y no leones que mantengan el arca es porque encima del altar no son decentes, porque todo género de animales, mascarones y vichos solo son para cosas profanas" 31 . Y es que en los simulacros divinos "solo se deue seguir la metáfora con ángeles chicos o grandes con atributos que hagan alusión al héroe que se adorna, por cuia razón en el remate del arca está el Amor Diuino sobre su esphera, flechando a Castilla por el maior obsequio y, al lado contrario, otro ángel con un león”. Bajo este argumento Herrera convirtió a los infantes en el motivo principal del penacho, bien sea agrupados, individualizados, en pequeñas dimensiones o corpulentos, como el putto que hacía sonar la trompeta de la fama o los que ofrecían el cetro y la corona al Amor Sagrado, si bien el elemento más novedoso, por su locuacidad y creatividad estética, era el arco de "piras o brasas del fuego que coronan el arca [que] están cada vna encima de cada virtud en consideración de lo que resplandecen las del santo" 32 . Un diseño complejo que debía entenderse como la abstracción barroca del nimbo de santidad que irradia la reliquia.

En el archivo de la catedral de Sevilla se conservan dos dibujos firmados por el antequerano Juan José del Carpio que, sin duda, responden a sendas copias

${ }^{30}$ [1674]. Sevilla. Informe de Bernardo Simón de Pineda sobre dos diseños para la urna de San Fernando y la reforma del presbiterio de la Capilla Real. A.C.S., Gobierno, Asuntos Despachados, leg. 9.783, exp. 4.

${ }^{31}$ Ibidem, f. [1].

32 1682, diciembre, 15. Madrid. Parecer ..., doc. cit., ff. [1]-[2v]. 
literales de los originales que Francisco de Herrera remitió con las instrucciones anteriores y que fueron devueltos a la corte una vez realizado su calco ${ }^{33}$. A sendas piezas, numeradas como 2 y 3 , les debió acompañar una primera que describiría la caja interior del relicario. Las trazas que se han conservado son claramente deudoras del quehacer plástico del artista cortesano tanto conceptual como técnicamente, si bien faltas del genio de su mano. Los dibujos están encajados mediante escuadra y cartabón, esbozados con grafito y perfilados mediante tinta parda, a la que posteriormente se ha animado con otras de colores y acuarelas, mostrando con todo lujo de detalles los cuantiosos motivos ornamentales y la suntuosa viveza de los materiales escogidos para su edificación.

El diseño número 2 describe el sepulcro exterior y la crestería del penacho, y cuenta con una solapa abatible que permite contemplar el arca interior, la caja con el difunto y el envés del frontal (Figura 2) ${ }^{34}$. El joyero que propone Herrera es una evolución barroquizante de los relicarios renacentistas y las arcas sacramentales ${ }^{35}$. Como había contemplado desde los bocetos de 1671, el sepulcro no se constriñe a ningún orden clásico, sino que se desarrolla anástilo, con un perfil abultado en su parte central y apenas secuenciado en el frente por gallones de motivos vegetales y querubines de clara inspiración romana. A partir de esta cadencia el pintor genera una trama horizontal que se trasdosa en el interior de la tapa como un marco liso que acoge tres cuadros con vegetación cartilaginosa, en cuyos interiores se contemplan una torre, un león y una tarja con una historia alusiva al bienaventurado (Figura 3). En el interior se visualiza la segunda urna compuesta por franjas metálicas recorridas por motivos calados. Y, tras los cristales, la caja con el difunto. La

33 Así había sucedido con los dos proyectos anteriores de Herrera el Mozo y debió suceder también con éste. [1671, octubre]. Madrid. Informe de Juan de Tejada que acompaña a diseños de urna y retablo remitidos a la Diputación del Santo Rey. A.C.S., Varios VIII, San Fernando, leg. 10.735, f. [2]. Recogido previamente en QUILES GARCÍA, F.: "En los cimientos...", op. cit., p. 219 , nota 80.

${ }^{34}$ [1682]. Dibujo de la urna de San Fernando número 2. A.C.S., Sección Capitular, Mapas y Planos, $n^{\circ} 105$. LUNA FERNÁNDEZ-ARAMBURU, Rocío y SERRANO BARBERÁN, Concha: Planos y dibujos del Archivo de la Catedral de Sevilla (Siglos XVI-XX). Sevilla, 1986, p. $175, \mathrm{n}^{\circ} 105$.

${ }^{35}$ Cruz Yábar vislumbra cierta inspiración compositiva y ornamental de Francisco de Herrera en el proyecto que el arquitecto Benavente realiza para el cuerpo incorrupto de San Diego de Alcalá, conservado en la capilla dedicada al bienaventurado en el convento de Santa María de Jesús de Alcalá de Henares. Sin embargo, intuimos que se trata, más bien, de una evolución "a la barroca" del modelo manierista de relicarios en forma de cáliz, tal y como sucede con las arcas de Jueves Santo durante los siglos XVII y XVIII o podemos contemplar, de manera más primitiva, en el sepulcro de San Isidro Labrador conservado en la colegiata madrileña del mismo nombre. CRUZ YÁBAR, Juan María: El arquitecto Sebastián de Benavente (1619-1689) y el retablo cortesano de su época (tesis doctoral). Madrid, 2013, p. 71 
tapadera externa del sepulcro es prácticamente plana, apenas recorrida por un conjunto de gallones y algunos elementos vegetales y angélicos. Sobre ella se desarrolla una crestería de roleos vegetales cuyo motivo central es un emblema dedicado a la dignidad y santidad del bienaventurado -compuesto por la espada guerrera y el cetro de la justicia sosteniendo la corona del reino de la que brota una rosa-jalonado por sendos ángeles que sostienen las armas de Castilla y León.

En este punto sugerimos la posibilidad de que el dibujo La rendición de Sevilla ante Fernando III, rey de Castilla y León (Figura 4) ${ }^{36}$, atribuido por Jonathan Brown al maestro sevillano, debe interpretarse como el boceto para la historia de la cartela central de la tapa interior del féretro. Así lo indica el tema escogido, el momento en que el monarca recibe las llaves de la ciudad de manos del vencido Axafat con la Giralda de fondo, signo del cabildo catedralicio, al igual que el formato apaisado. Y, sobre todo, el tratamiento plástico del conjunto, que parece aludir a un posible trabajo metálico bajo las normas del schiacciato, diferenciándose con claridad tres planos que van desde la elegancia y estilización de los protagonistas, perfectamente detallados, hasta el abocetamiento de los paisajes y el agolpamiento del ejército. Lo que, traducido a labor escultórica, supondría trabajar desde el altorelieve al grabado.

Por su parte, en el dibujo número 3 de Juan José del Carpio se contempla el conjunto del sepulcro-relicario y su pedestal (Figura 5) ${ }^{37}$. La mesa de altar se eleva con un leve peldaño de piedra roja y queda oculta por un frontal que cuenta con una caja metálica dorada. Sobre este podio descansa un historiado pedestal de gran molduración compuestos por mármoles polícromos y apliques de bronce que simulan vegetación, roleos y cariátides, reservándose el centro de esta trama a la inscripción canónica de la canonización del difunto. La cama del arca se prolonga hacia ambos lados con un voladizo bulboso del que parten sendos pilares vegetales de cuantiosa decoración que se desarrollan por encima del penacho hasta envolver por completo el relicario. Este elemento metálico es simétrico y concluye en un pequeño doselete circular peraltado del que pende un telar rojo. La pieza se remata con la imagen del Amor Sacro simbolizado en una mujer togada que eleva la cruz y la espada.

Con este proyecto definido entre las manos, y gracias al remanente de 9.000 pesos reunidos en distintos llamamientos a tierras de ultramar, el arzobispo puso

${ }^{36}$ Museo del Louvre, sig. 18.422. Atribuido por BROWN, Jonathan: "Drawings by Herrera the Younger and Follower", Master of Drawings, 13, 3, 1975, pp. 238-239. Pérez Sánchez entendió este dibujo como el esbozo de un grabado. PÉREZ SÁNCHEZ, Alfonso Emilio y BOUBLI, Lizzie: Dessins spagnols: Maîtres des XVI et XVII siècles. París, 1991, pp. 144-145, cat. 66 .

${ }^{37}$ [1682]. Dibujo de la urna de San Fernando número 3. A.C.S., sección Capitular, Mapas y Planos, $\mathrm{n}^{\circ}$ 104. LUNA FERNÁNDEZ-ARAMBURU, R. y SERRANO BARBERÁN, C.: Planos..., op. cit., p. 175, nº 106. 
en marcha los trámites necesarios para iniciar su ejecución ${ }^{38}$, dando comienzo con la tasación del interior por José Portillo valorándola en 12.400 pesos, a repartir entre los 1.000 del arca de cristales, 4.800 de la zona de plata calada y 6.600 de la plata sobredorada ${ }^{39}$.

En paralelo a la gestión de las urnas los responsables de la capilla consensuaron la remodelación de su cabecera bajo la propuesta de doble presbiterio con escalinatas laterales defendida por Matías de Arteaga y Bernardo Simón de Pineda en 1673, pero manteniendo la idea de un retablo de piedras polícromas y apliques metálicos ideado por Mozo. El nuevo y definitivo programa arquitectónico se componía de dos alturas. La inferior apenas se elevaría un palmo del suelo de la nave del templo por un peldaño y correspondería al área de influencia del presbiterio de la reliquia de San Fernando. La superior sería mucho más amplia, ocuparía todo el frente del ábside y llegaría a elevarse otros tres peldaños en el centro para alzar el altar y retablo de la Virgen de los Reyes. Entre ambos niveles discurrirían dos gradas paralelas compuestas por diez peldaños de tres varas de ancho. Según la tasación realizada por el arquitecto José Granado de la Barrera, para estos escalones y recrecimientos se necesitarían 132 varas lineales de jaspes colorados de gran calidad y pulimento. El mismo material sería utilizado para marcar las cornisas que sobresalían de la grada superior, mientras que para la solería se haría uso de 78 varas cuadradas de piedras de colores. En el perfil de las escaleras se dispondría un barandal compuesto por balaustres de jaspe con pasamanos y rodapiés de piedras polícromas. Este mismo antepecho se repetiría en el perímetro de la urna a menor altura y contando con apertura en sus tres frentes, donde se disponen puertas metálicas abatibles. En total la obra contaría con 145 balaustres y 14 pilastras decoradas por intarsias de piedras de colores y remates que se colocarían en las esquineras. El proyecto incluía dos tribunas "con sus recibimientos que suban desde el suelo con la grandeza y buena disposizión y bariedad de jaspes y moldados que en dichos sitios pide"; y dos postigos ornamentados "con motilillos de diferentes piedras y coronaciones" que harían de puertas de la bóveda sepulcral. Todo lo cual se estimaba aproximadamente en 146.970 reales y 4 años de labor, incluido el coste del basamento del santo, según dibujo e indicaciones realizadas por Francisco de Herrera, "siendo de jaspes diferentes, labrados y embutidos por dentro y fuera la coronación" 40 .

${ }^{38}$ 1683, febrero, 15. Sevilla. Capítulo. Recogido de SANCHO CORBACHO, H.: "Historia...", op. cit., p. 117. El documento original no ha podido ser consultado dado que en la actualidad falta el libro de Autos Capitulares del arco cronológico que va desde 1683 a 1691.

39 1683, agosto, 24. Sevilla. Ajuste de la urna de San Fernando realizado por José Portillo. A.C.S., Gobierno, Asuntos Despachados, leg. 9.783, exp. 4.

${ }^{40}$ HERRERA GARCÍA, Francisco Javier: "De mármoles mixtos coloreados. El proyecto de retablo mayor para la Capilla Real de Sevilla (1683-1694) y su debate 
Debe advertirse que el interés por los mármoles, las piedras y el bronce en la trama de la capilla supone una importante novedad en el entorno artístico hispalense, consecuencia directa - como puntualiza Pineda-del carácter regio y fúnebre que se pretende explicitar ${ }^{41}$. Hacía más de una década que el Mozo había introducido este suntuoso planteamiento entre sus paisanos y aún los postulaba para proyectos similares como su diseño para el retablo de la Virgen de la Almudena de $1682^{42}$. Pero, como bien indica el profesor Herrera García, fue con la llegada de Jaime de Palafox y Cardona a la mitra local, procedente del obispado de Palermo, cuando la intarsia adquiere mayor presencia ${ }^{43}$. Al fin y al cabo, el nuevo arzobispo y el maestro mayor son viejos conocidos y parecen entenderse a la perfección ${ }^{44}$. Con Palafox se comenzó a concretar el proyecto con la ejecución de las primeras piezas del sepulcro-relicario gracias a la búsqueda de las nuevas vías de financiación y al empecinamiento personal del prelado.

El verano de 1685 supuso un punto de inflexión en todo el proceso. El 25 de agosto muere Herrera el Mozo y con él cualquier defensa de sus planteamientos. Por suerte, pocos días antes del fallecimiento el maestro había dejado atado y encarrilado el proyecto de las urnas. Para entonces la Cámara de Castilla había remitido al prelado y al asistente hispalense, Luis de Salcedo y Arbizu, su voluntad de avalar las trazas del sepulcro concretadas por el maestro mayor en respuesta al peritaje remitido el 18 de marzo por Juan Laureano de Pina y José Portillo $^{45}$. En su evaluación los plateros sevillanos habían puesto de relieve todas las complicaciones técnicas que entrañaba la ejecución de la caja más próxima al difunto, dada la delgadez de los detalles, la dificultad de las uniones, el abombamiento de la tapa y el hecho de tener que trabajar con chapas de plata muy

internacional", Anuario del Departamento de Historia y Teoría del Arte, 24, 2012, p. 52, nota 12. 1683, diciembre, 21. Sevilla. Parecer y ajuste de las obras de la Capilla Real por José Granado de la Barrera. A.C.S., Gobierno, Asuntos Despachados, leg. 9.783, exp. 4.

${ }^{41}$ 1685, septiembre, 6. Sevilla. Bernardo Simón de Pineda compara la obra marmórea de la capilla con el Panteón Real del monasterio del Escorial y el ochavo de la catedral de Toledo.

42 CRUZ YÁBAR, Juan María: "El juego de altar de coral del Museo Arqueológico Nacional y otras obras de plata del siglo XVII de la Virgen de la Almudena de Madrid", Estudios de platería: San Eloy, 2011, pp. 192-193.

${ }^{43}$ Véase HERRERA GARCÍA, F. J.: “De mármoles...”, op. cit., pp. 49-68.

${ }^{44}$ Jaime de Palafox y Cardona es arcipreste de Santa María del Pilar de Zaragoza y diputado del reino de Aragón en el momento en que se realiza el concurso para el diseño del nuevo edificio congregacional y cuando las trazas Francisco de Herrera el Mozo, como maestro mayor de Obras Reales, se imponen definitivamente.

45 1685, agosto, 14. Madrid. Carta de Íñigo Fernández del Campo al arzobispo de Sevilla sobre la traza de la urna de San Fernando. A.C.S., Gobierno, Asuntos Despachados, leg. 9.783, exp. 5. La Cámara pide, no obstante, que tanto el prelado como el asistente contacten con los profesionales de mayor validez para peritar nuevamente las trazas. 
grandes, disparando el precio de su realización hasta los 12 pesos por marco, contando la obra con un total de $340 \operatorname{marcos}^{46}$.

A dichas indicaciones el diseñador había respondido el 26 de abril, contrariado ante el hecho de que el precio se hubiera ajustado por marco, dado que el grosor del metal difería según el vaciado que requiere cada sección. Igualmente, había negado el uso de bronce frente al cobre que se propone, aduciendo que la aleación no se podía trabajar con el martillo y el cincel. Y que, por el contrario, se trataba de un metal incorruptible y más perdurable en su color dorado, para finalmente proponer que las figuras en bulto redondo -virtudes, ángeles y otros ornamentos-debían ser ejecutadas a partir de modelos encargados a un buen escultor que supiera interpretar su traza ${ }^{47}$.

Por caprichos del destino Francisco de Herrera se quedó a las puertas de conocer el desenlace de una de sus obras más deseadas.

El 23 de septiembre Laureano de Pina, siguiendo las indicaciones cortesanas, volvió a tasar la caja, previa indicación de la inoperancia de la consulta realizada al difunto pintor que había confundido la urna exterior con la pieza interna. La caja que ahora se trataba de realizar era la de metal dorado, por dentro y por fuera. Esta pieza debía realizarse entera con chapas - “así en los liensos como en sus boseles y medias cañas" y suelo- unidas por fajas y tornillos metálicos a lo largo de sus dos varas y media de longitud, debiéndose ajustar con puntualidad al perfil de la urna que recibe y mostrarse al exterior bien lisa y plomada, con la dificultad que ello implica. Además, esta caja debía contar con un frontal abatible en sus dos mitades, de modo que había que embutir y disimular cerrojos y goznes. Y, sobre todo, debía dorarse con azogue por la longitud de las chapas, con el consiguiente riesgo para la salud. Para solventar el tema del precio, el maestro ajustó su trabajo hasta los 10 pesos por marco, más 4 del montaje final y 6 del dorado -contando metal, trabajo y bruñido-, achacando la rebaja de la cuantía inicial a su devoción al bienaventurado ${ }^{48}$.

${ }^{46}$ 1685, marzo, 18. Sevilla. Tasación de la obra de la urna de San Fernando por Juan Laureano de Pina y José Portillo. A.C.S., Gobierno, Asuntos Despachados, leg. 9.783, exp. 6.

47 1685, abril, 26. Madrid. Informe de Francisco de Herrera mandada por carta del marqués de Peñaranda. A.C.S., Gobierno, Asuntos Despachados, leg. 9.783, exp. 6.

${ }^{48}$ 1685, septiembre, 23. Sevilla. Tasación de Juan Laureano de Pina de la urna de San Fernando diseñada por Francisco de Herrera. A.C.S., Gobierno, Asuntos Despachados, leg. 9.783, exp. 6. Recogido previamente en HERRERA GARCÍA, F. J.: "De mármoles...", op. cit., pp. 54, nota 29. Este documento se adjunta a la respuesta que el prelado realiza a la misiva de 14 de agosto de Íñigo Fernández del Campo. 1685, septiembre, 25. Sevilla. Respuesta del arzobispo de Sevilla al rey sobre el coste de la urna de San Fernando. A.C.S., Gobierno, Asuntos Despachados, leg. 9.783, exp. 6. En ella se vuelve a indicar "cómo don Francisco de Herrera, maestro mayor de las Obras Reales, pareçe que padeçió 
Precio, técnica y diseño final fueron aprobados por la Cámara de Castilla dos semanas más tarde ${ }^{49}$, recayendo el encargo sobre Juan Laureano de Pina, con el apoyo de otros tres maestros sevillanos, por obligación de contrato firmada el 7 de noviembre ante el escribano Miguel Pastor ${ }^{50}$, manteniéndose al frente de la hechura del sepulcro, ya de manera autónoma, durante los 34 años en los que se prolonga su accidentada ejecución ${ }^{51}$.

En definitiva, resulta llamativo cómo, durante el medio siglo que ocupa este largo y dilatado proceso, el proyecto de urna-relicario de Herrera el Mozo sobrevivió sin apenas variación hasta su conclusión en septiembre de $1719^{52}$, mientras que el diseño marmóreo del retablo mayor no corrió la misma suerte, siendo objeto de amplias discusiones y de diferentes proyectos que nunca prosperaron ${ }^{53}$, llegándose a rechazar de plano tras un concurso llevado a cabo en $1689^{54}$. Esta

equiuocación, entendiendo se hablaba de la caxa exterior en lo que de la interior se decía" y el esfuerzo realizado por Laureano de Pina para ceñir el precio final de la misma.

49 1685, octubre, 9. Madrid. Carta de Íñigo Fernández del Campo al arzobispo de Sevilla sobre la aprobación del precio de la urna de San Fernando. A.C.S., Gobierno, Asuntos Despachados, leg. 9.783, exp. 6; 1685, octubre, 16. Madrid. Íñigo Fernández del Campo envía al arzobispo de Sevilla el despacho de Carlos II por el que manda colocar el cuerpo de San Fernando en la forma que se dispone. A.C.S., Gobierno, Asuntos Despachados, leg. 9.783, exp. 5. Esta nueva documentación que aportamos viene a refrendar lo dispuesto en el cabildo de los capellanes reales de 13 de octubre de 1685 que fue recogido en SANCHO CORBACHO, H.: "Historia...", op. cit., pp. 105 y 117. Hoy no se puede comprobar por encontrarse en paradero desconocido el libro de autos que lo contiene.

${ }^{50}$ La huella de este contrato fue puesta de manifiesto en QUILES GARCÍA, F.: "En los cimientos...", op. cit., p. 223, nota 113 .

${ }^{51}$ Sobre el proceso de ejecución de las urnas de San Fernando véase SANCHO CORBACHO, H.: "Historia...", op. cit., pp. 105-114 y 118-136; y SANZ SERRANO, María Jesús: Juan Laureano de Pina. Sevilla, 1981, pp. 65-95.

${ }^{52}$ No en vano el propio Bernardo Simón haría una maqueta tridimensional de las cajas que, según la descripción conservada, parece respetar todos los criterios propuestos por el maestro mayor. 1690, junio, 10. Sevilla. Contrato de la realización de la urna de San Fernando entre el arzobispo de Sevilla y Juan Laureano de Pina. A.C.S., Varios VIII, San Fernando, leg. 37 (7), carpeta 4. Documento recogido previamente en QUILES GARCÍA, F.: "En los cimientos...", op. cit., pp. 232-234. El único elemento del conjunto argénteo que varió sustancialmente en su forma final fue el pabellón superior, cuyos roleos y balaustres contaron con diferentes diseños, entre otros uno de Pineda de 1689 y varios dibujos conservados en el Archivo de la Catedral, si bien, incluso en este cambio, se mantiene en lo sustancial la idea de vibración y aura que pretendía el Mozo en su traza.

${ }^{53}$ La Virgen de los Reyes, en fecha indeterminada pero no muy lejana a 1690, volvió a su tabernáculo, no sin antes adecuarse el espacio con una adaptación del testero realizada por Pineda, y nunca más se varió el testero. Así se dispone en un documento sin fechar ni localizar recogido en SANCHO CORBACHO, H.: "Historia...", op. cit., pp. 134-136.

${ }^{54}$ A propósito del retablo de la Virgen de los Reyes véase HERRERA GARCÍA, F. J.: "De mármoles...", op. cit., pp. 52-64. 
disparidad de criterios ante sendos planes que se proponían indisolubles debe atribuirse a una prolongación innecesaria de los tiempos y a la consecuente elevación de los $\operatorname{costes}^{55}$, pero también a la falta de profesionales cualificados en materia marmórea y a una serie de parámetros estéticos irreconciliables entre la corte y Sevilla. Y es que el contraste visual pretendido por el Mozo entre la sobriedad del juego arquitectónico del retablo y la exuberancia de la urna nunca había sido bien comprendida por sus paisanos, que se encontraban mucho más cercanos a la carnosidad y voluptuosidad del sepulcro que al descarnado y elegante barroquismo de las formas del tabernáculo.

Fecha de recepción: 28 de septiembre de 2016

Fecha de aceptación: 6 de abril de 2017

${ }^{55}$ La tasación de los distintos proyectos que se van sucediendo en el orden de la narración anteriormente expuesta puede contemplarse en cómo aumenta con celeridad el coste real de la obra, una consecuencia derivada de la estrategia esgrimida en 1671 por Juan de Tejada sobre la rebaja irreal del precio global a fin de propiciar el favor cortesano. 


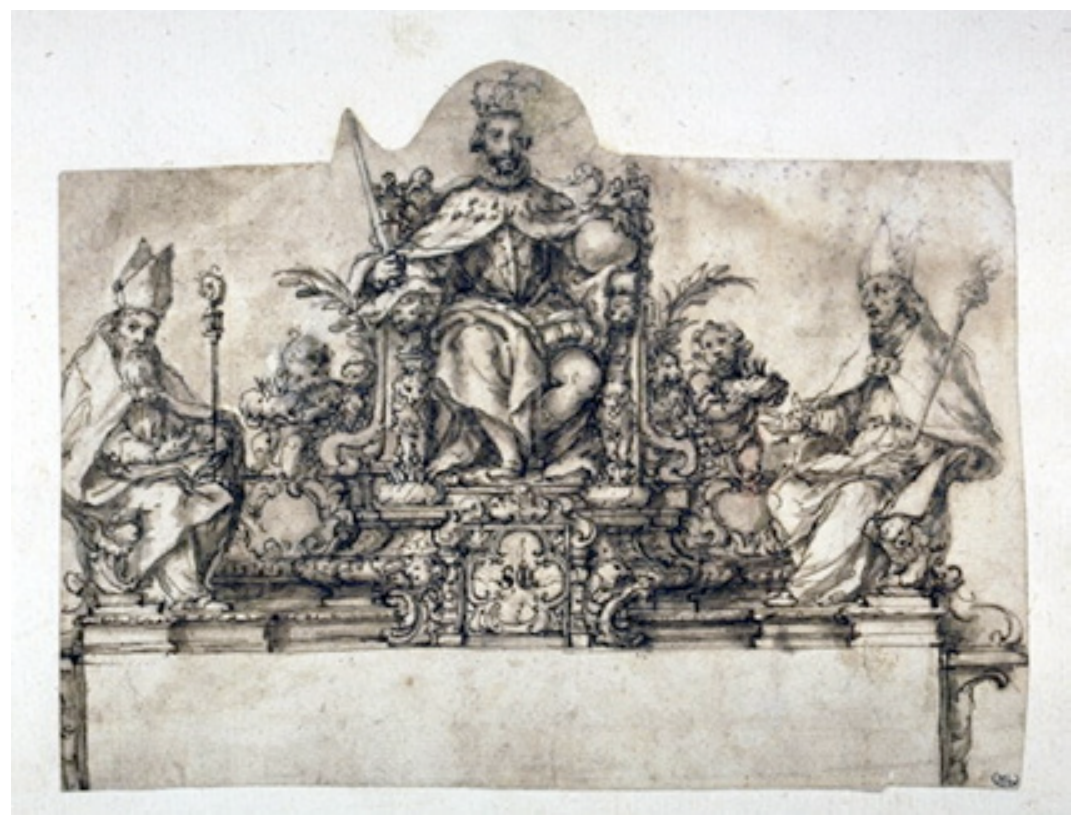

Figura 1. Juan de Valdés Leal, San Fernando entronizado, 1681-1682, Museo del Louvre, sig. 43253.

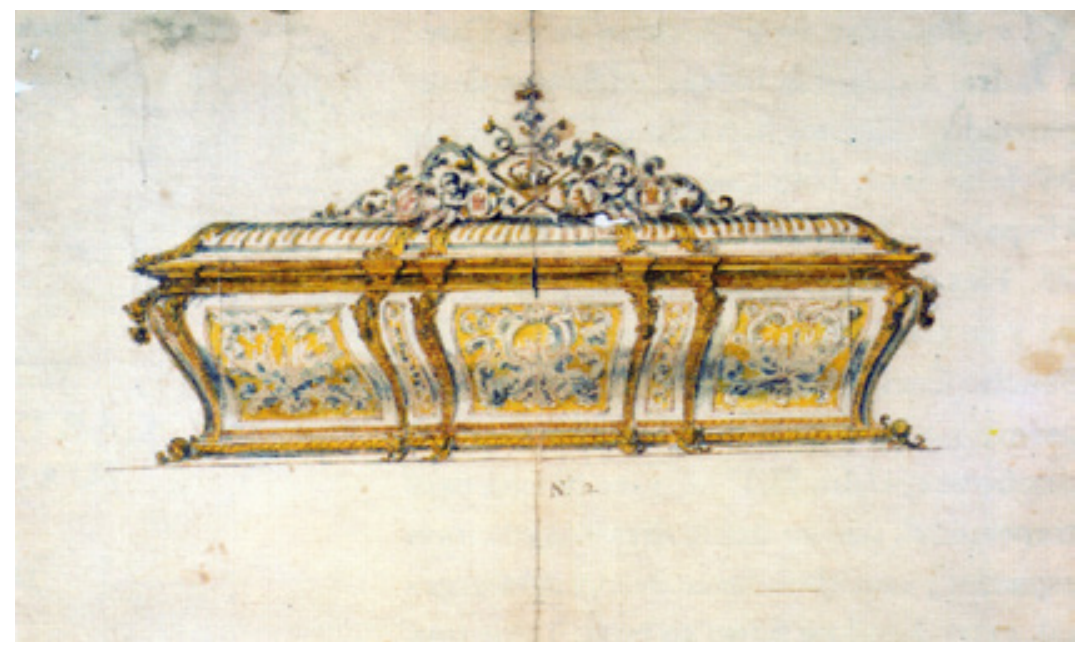

Figura 2. Juan José del Carpio, Dibujo de la urna de San Fernando, diseño número 2 (con la solapa cerrada), hacia 1682, copia de original de Francisco de Herrera el Mozo, Archivo Catedral de Sevilla, Mapas y Planos no 105. 


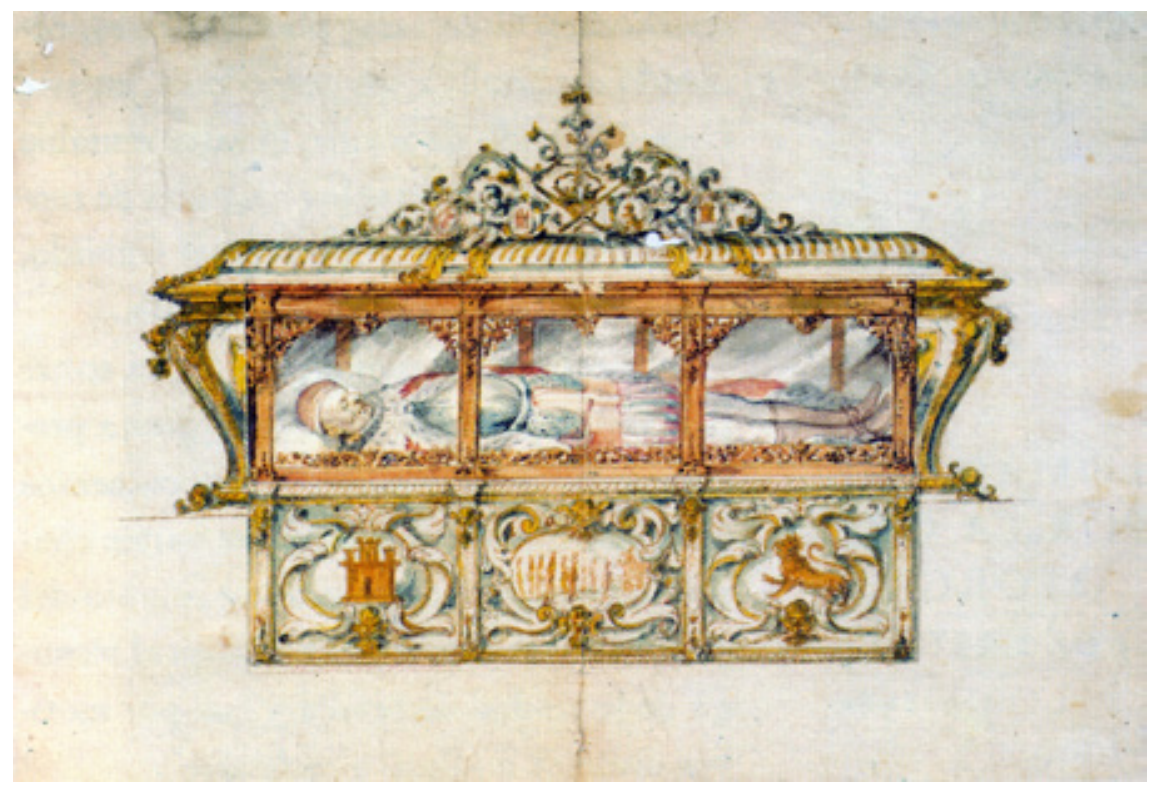

Figura 3. Juan José del Carpio Dibujo de la urna de San Fernando, diseño número 2 (con la solapa desplegada), hacia 1682, copia de original de Francisco de Herrera el Mozo, Archivo Catedral de Sevilla, Mapas y Planos no 105.

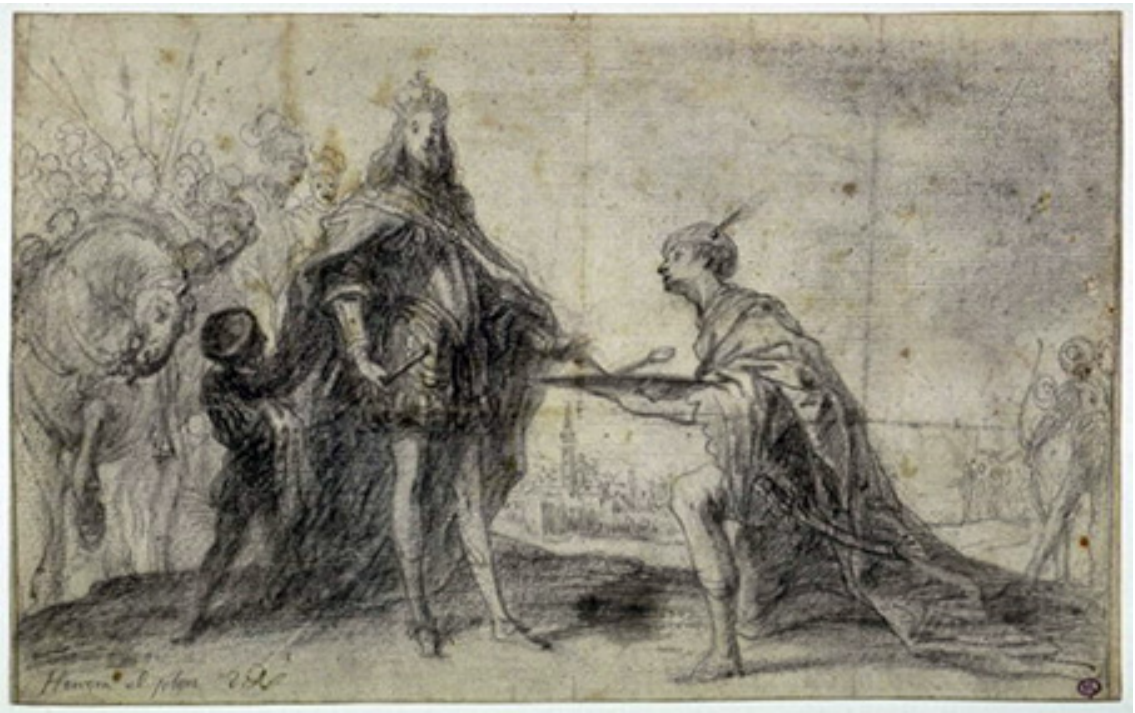

Figura 4. Francisco de Herrera el Mozo, La rendición de Sevilla ante Fernando III, rey de Castilla y León, 1682, Museo del Louvre, sig. 18422. 


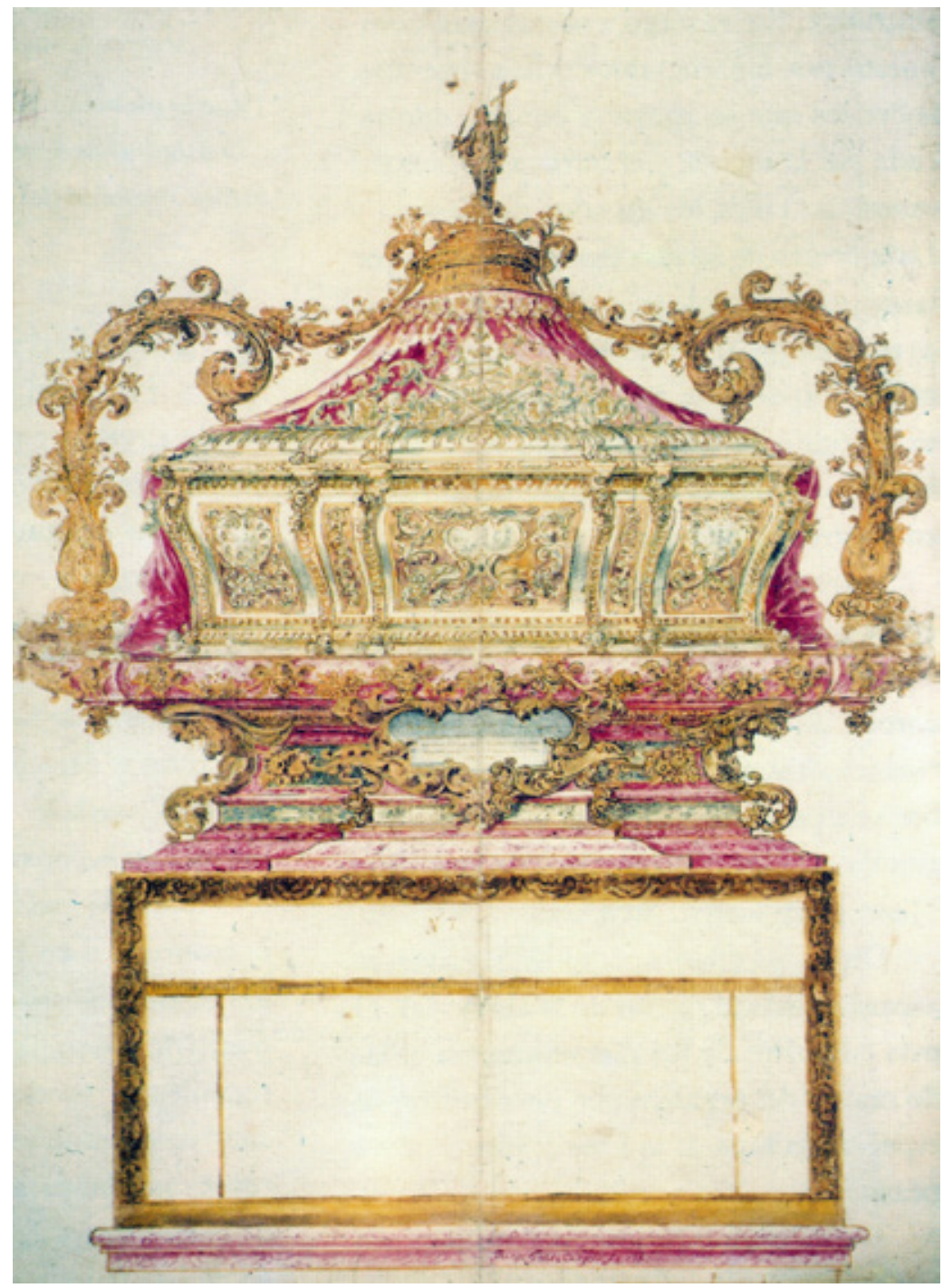

Figura 5. Juan José del Carpio, Urna de San Fernando, diseño número 3, hacia 1682, Archivo Catedral de Sevilla, Mapas y Planos no 106. 